Gut, 1981, 22, 257-263

\title{
Effect of intestinal surgery on the risk of urinary stone formation
}

\author{
C P BAMBACH, W G ROBERTSON, M PEACOCK, * AND G L HILL
}

From the University Department of Surgery and MRC Mineral Metabolism Unit, The General Infirmary, Leeds

SUMMARY The prevalence of urinary stone disease in 426 patients who had undergone bowel surgery at the General Infirmary at Leeds from 1958 to 1978 was found by postal questionnaire to be $9.4 \%$. The risk of urinary stone formation was determined from the composition of 24 hour urines from 61 unselected patients, in whom intestinal resections had been performed. There were 27 patients with an ileostomy, 17 patients with an ileostomy and a small bowel resection, and 17 patients with a small bowel resection, or bypass, and an intact colon. Of this group of 61 patients, $9.8 \%$ gave a history of urinary stones after surgery. Compared with normal control subjects ileostomy patients had significantly lower urinary $\mathrm{pH}$ and volume, higher concentrations of calcium, oxalate, and uric acid, and increased risk of forming uric acid and calcium stones: a small bowel resection combined with an ileostomy increased the ileostomy output, lowered the urinary volume further, and reduced urinary calcium excretion. The concentration of urinary oxalate increased and the risk of both uric acid and calcium stones was high. Patients with small bowel resection and intact colon had hyperoxaluria and an increased risk of calcium stones despite a low urinary calcium. There was no increased risk of uric acid stones in this sub-group. It is concluded that the risk of forming urinary stones after this type of surgery is considerable. The follow-up of patients with ileostomies and with small bowel resections should include an assessment of faecal losses and urinary composition to identify the patients who have a high risk of forming urinary stones.

It has been appreciated for some time that urinary stone formation is a complication of inflammatory bowel disease and of the surgical management of the condition. ${ }^{1-4}$ An understanding of the aetiology of such stone formation is essential for the prevention and treatment of stone disease in this group of patients.

The prevalence of urinary stones in ileostomy patients is between 7 and $18 \%^{1-4}$ compared with a maximum of $3.8 \%$ in the general population. ${ }^{5}$ Uric acid stones usually comprise less than $10 \%$ of all stones ${ }^{6-8}$ but make up $60 \%$ of stones found in patients with an ileostomy. ${ }^{19}$ Clarke and McKenzie have defined the main urinary abnormalities which produce uric acid stones in ileostomy patients ${ }^{10}$ but the causes of calcium oxalate stone formation and the effect of small bowel resection, in the presence of an ileostomy, on the risk of stone formation has not been investigated.

*Address for correspondence and reprints : Dr Munro Peacock, MRC Mineral Metabolism Unit, The General Infirmary, Leeds LS1 3EX.

Received for publication 22 October 1980
Calcium oxalate stone formation is a complication of inflammation or resection of the distal ileum and of jejunoileal bypass for morbid obesity. ${ }^{11-13}$ Although most studies suggest that hyperoxaluria occurs only with an intact colon ${ }^{14}$ it may also occur in ileostomy patients in certain circumstances. ${ }^{1516}$

Urinary composition -in particular, its influence on the saturation of urine with stone-forming saltsis the major factor in determining the risk of stone formation. ${ }^{17-20}$ The urinary risk factors for calcium stone disease, as assessed on a 24 hour collection, can be combined to give a measure of the relative probability of stone formation (PSF). ${ }^{19}$ The values of the saturation indices for both uric acid and calcium oxalate and the PSF values are generally higher in stone-formers than in normal subjects and so may be used to assess the relative risk of stone formation in different groups of patients.

In order to clarify the relationship between intestinal resection and the risk of forming urinary stones we have measured urinary composition and assessed the saturation indices for both uric acid and calcium stones and the PSF for calcium stones 
in patients with an ileostomy, with an ileostomy and small bowel resection, and with a small bowel resection, or bypass, and an intact colon.

\section{Methods}

\section{PATIENTS STUDIED}

The prevalence of urinary stone disease in patients who had undergone bowel surgery in the Department of Surgery at the General Infirmary at Leeds from 1958 to 1978 was established by postal questionnaire. The questions were designed to detect a history of the passage of a urinary stone after intestinal surgery, a history of a urinary stone identified by radiography, or a history of surgica removal of a stone from the urinary tract. The total number of patients contacted was 583 and formed three groups according to the type of surgical procedure. The first had undergone a proctocolectomy and ileostomy and had less than $10 \mathrm{~cm}$ of small bowel resected. The second were similar to the first but had between 20 and $300 \mathrm{~cm}$ of small bowel resected. The third did not have an ileostomy but had between 50 and $300 \mathrm{~cm}$ of small bowel resected. The mean time since surgery was $8 \pm 1$ years (mean $\pm \mathbf{S E}$ ).

Sixty-one patients attending for routine surgical follow-up agreed to collect a 24 hour urine on a free diet. None was specifically referred for assessment of urinary stone disease. The patients formed three groups according to the nature of their previous intestinal surgery. There were 27 patients who had undergone proctocolectomy and ileostomy with less than $10 \mathrm{~cm}$ of small bowel resected. Seventeen patients had undergone proctocolectomy and ileostomy and also had between 20 and $300 \mathrm{~cm}$ of small bowel resected. Fourteen patients had between

Table 1 Details of patients in whom urinary studies were performed

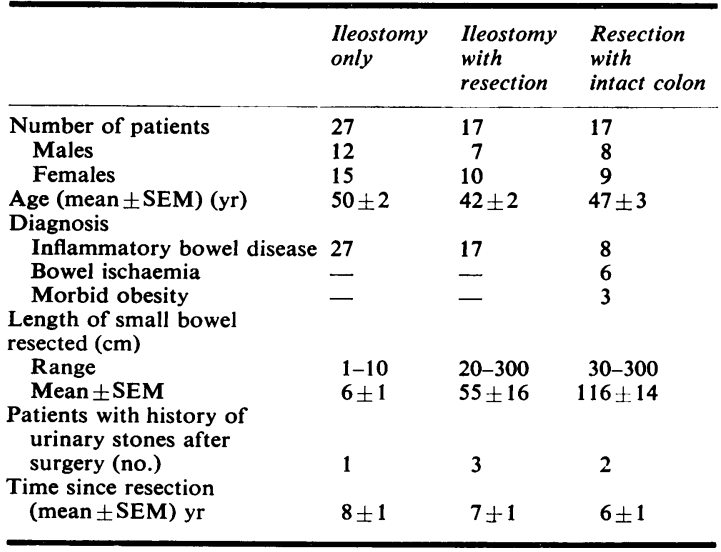

30 and $300 \mathrm{~cm}$ of small bowel and the caecum or ascending colon resected and three patients had a jejunoileal bypass performed leaving $55 \mathrm{~cm}$ of small bowel and the entire colon in continuity.

Table 1 summarises the clinical details of patients in whom urinary studies were performed. One patient in the ileostomy-only group was taking allopurinol for gout, but had no history of urinary stones. In the ileostomy with resection group, two patients were taking long-term, low dose steroids for Crohn's disease and one other patient was taking a diuretic. In the resection with intact colon group one patient was taking steroids for Crohn's disease. All patients were studied as outpatients on a free diet. Six patients $(9 \cdot 8 \%)$ gave a history of passing urinary stones after surgery.

\section{CONTROL PATIENTS}

Three control groups were studied. The normal control group consisted of 85 subjects $^{21}$ who were not significantly different from the study groups in terms of age and sex. The two groups of stone formers consisted of 23 patients with idiopathic uric acid stones ${ }^{22}$ and 56 patients with idiopathic calcium stones. ${ }^{21}$

\section{URINE AND FAECAL ANALYSIS}

A 24 hour urine was collected from each patient and the ileostomy effluent collected and weighed for the same 24 hour period in 36 of the 44 ileostomy patients. The urines were analysed for $\mathrm{pH}$, volume, calcium, phosphate, oxalate, uric acid, glycosaminoglycan inhibitors (GAGS), sodium, and potassium by methods previously described. ${ }^{23}{ }^{24}$

\section{CALCULATIONS AND STATISTICAL ANALYSIS}

The mean values, and standard errors, or each constituent of urine were calculated for the three study groups and the three control groups. The significance of the differences between groups was assessed using Student's $t$ test.

Relative supersaturation indices for uric acid and calcium oxalate were obtained for each patient from nomograms ${ }^{20}$ and the relative probability of calcium stone formation (PSF) was calculated for each

Table 2 Prevalence of urinary stones after surgical treatment of inflammatory bowel disease

\begin{tabular}{lrrrr}
\hline & $\begin{array}{l}\text { Number } \\
\text { questioned }\end{array}$ & $\begin{array}{l}\text { Number } \\
\text { replied }\end{array}$ & Stones & $\begin{array}{l}\text { Percent } \\
\text { with stone }\end{array}$ \\
\hline $\begin{array}{l}\text { Ileostomy only } \\
\begin{array}{l}\text { lleostomy plus small } \\
\text { bowel resection }\end{array}\end{array}$ & 400 & 305 & 27 & 8.9 \\
$\begin{array}{l}\text { Small bowel resection } \\
\text { with intact colon }\end{array}$ & 95 & 61 & 9 & 14.8 \\
\begin{tabular}{l} 
All patients \\
\hline
\end{tabular} & 583 & 426 & 40 & \\
\hline
\end{tabular}


Table 324 hour excretion of urinary constituents

\begin{tabular}{|c|c|c|c|c|}
\hline & $\begin{array}{l}\text { Normal controls } \\
n=85 \\
\text { mean } S E M\end{array}$ & $\begin{array}{l}\text { Ileostomy only } \\
n=27 \\
\text { mean } S E M\end{array}$ & $\begin{array}{l}\text { Ileostomy wth resection } \\
n=17 \\
\text { mean SEM }\end{array}$ & $\begin{array}{l}\text { Resection with intact colon } \\
n=17 \\
\text { mean SEM }\end{array}$ \\
\hline $\begin{array}{l}\text { Volume (l) } \\
\text { pH } \\
\text { Calcium (mmol) } \\
\text { Oxalate (mmol) } \\
\text { GAGS (mg) } \\
\text { Uric acid (mmol) } \\
\text { Sodium (mmol) } \\
\text { Potassium (mmol) }\end{array}$ & $\begin{array}{c}1 \cdot 70 \pm 0.07 \\
6 \cdot 12 \pm 0.05 \\
4.59 \pm 0.24 \\
0.29 \pm 0.01 \\
23.3 \pm 1.0 \\
3.61 \pm 0.09 \\
172 \pm 8 \\
59 \pm 3\end{array}$ & $\begin{aligned} 0 \cdot 99 & \pm 0 \cdot 07 \dagger \\
5 \cdot 24 & \pm 0 \cdot 05 \dagger \\
4 \cdot 37 & \pm 0 \cdot 40 \\
0 \cdot 29 & \pm 0 \cdot 01 \\
16 \cdot 9 & \pm 0 \cdot 9 \dagger \\
3 \cdot 42 & \pm 0 \cdot 19 \\
79 & \pm 8 \dagger \\
62 & \pm 5\end{aligned}$ & $\begin{array}{c}0.72 \pm 0 \cdot 11 \dagger \\
5 \cdot 42 \pm 0.07 \dagger \\
2 \cdot 45 \pm 0.68 * \\
0.31 \pm 0.03 \\
14 \cdot 0 \pm 1 \cdot 5 \dagger \\
2.94 \pm 0 \cdot 26 \\
23 \pm 9 \dagger \\
52 \pm 7\end{array}$ & $\begin{array}{c}1 \cdot 36 \pm 0 \cdot 14 \\
5 \cdot 75 \pm 0 \cdot 10 \\
1 \cdot 48 \pm 0 \cdot 31 \dagger \\
0 \cdot 60 \pm 0.08 \\
20 \cdot 8 \pm 3 \cdot 0 \\
3 \cdot 07 \pm 0.33 \\
135 \pm 11 \\
68 \pm 7\end{array}$ \\
\hline
\end{tabular}

${ }^{*} \mathrm{P}<0.01$. $\quad+\mathrm{P}<0.001$ compared with normal controls, using Student's $t$ test.

patient from the formula previously described. ${ }^{19} \mathrm{This}$ index is based on a combination of urinary risk factors derived from the comparison of the urinary biochemistry of a stone-forming population related to that of a normal control population. The significance of differences between the three study groups, and the three control groups was assessed using the Wilcoxon signed-rank test.

\section{Results}

The response to the questionnaire was 426 out of 583 patients. The overall prevalence of urinary stones in this group was 40 out of $426(9.4 \%)$. The highest prevalence of urinary stone was in the ileostomy with small bowel resection group and the lowest in the small bowel resection with intact colon group (Table 2).

The 24 hour excretions of urinary constituents are shown in Table 3 for the three groups of patients and for normal controls. Compared with normal subjects, the ileostomy-only group had a significant reduction in urine volume, $\mathrm{pH}, \mathrm{GAGS}$, and sodium $(\mathrm{P}<0.001)$. The ileostomy with resection group had a significant reduction in urine volume, $\mathrm{pH}, \mathrm{GAGS}$, and sodium $(\mathrm{P}<0.001)$ and calcium $(\mathrm{P}<0.01)$. The resection with intact colon group had a significant reduction in calcium $(\mathrm{P}<0.001)$ and a significant increase in oxalate $(\mathrm{P}<0.001)$.

The urine volume and urinary sodium were significantly lower in the ileostomy with resection group than in the ileostomy-only group $(\mathrm{P}<0.05)$.

The concentrations of calcium, oxalate, GAGS, and uric acid are shown in Table 4 for the three groups of patients and the normal controls. Despite normal 24 hour excretions of these ions, there were significant increases in the concentrations of calcium, oxalate and uric acid $(\mathrm{P}<0.001)$ in the ileostomy-only group compared with normal subjects. The ileostomy with resection group had a significant increase in the concentration of oxalate and uric acid $(\mathrm{P}<0.001)$ but not of calcium. The resection with intact colon group had a significant increase in the concentration of oxalate $(P<0.001)$, and a significant decrease in the concentration of calcium $(\mathrm{P}<0.001)$. The uric acid concentration in this group was normal. The concentration of GAGS was normal in all three groups.

Table 5 shows the mean logarithm of relative supersaturation of urine with respect to uric acid for the patients in the three study groups compared with the mean for normal controls and idiopathic uric acid stone-formers. The values for the two groups of ileostomy patients were significantly higher than those of the normal controls $(\mathrm{P}<0.001)$. There was no significant difference between the two groups of ileostomy patients. However, the ileostomy-only group had significantly lower uric acid saturation values than the idiopathic uric acid stone-formers $(P<0.05)$, while the ileostomy with resection group did not. The values for the resection with intact colon group were not significantly different from those of the normal controls.

The mean relative supersaturation of urine for calcium oxalate for the patients in the three study groups and for normal controls and idiopathic

Table 4 Concentrations of urinary constituents

\begin{tabular}{|c|c|c|c|c|}
\hline & $\begin{array}{l}\text { Normal controls } \\
n=85 \\
\text { mean } S E M\end{array}$ & $\begin{array}{l}\text { Ileostomy only } \\
n=27 \\
\text { mean } S E M\end{array}$ & $\begin{array}{l}\text { Ileostomy with resection } \\
n=17 \\
\text { mean SEM }\end{array}$ & $\begin{array}{l}\text { Resection with intact colon } \\
n=17 \\
\text { mean SEM }\end{array}$ \\
\hline $\begin{array}{l}\text { Calcium }(\mathrm{mmol} / \mathrm{l}) \\
\text { Oxalate }(\mathrm{mmol} / \mathrm{l}) \\
\text { GAGS }(\mathrm{mg} / \mathrm{l}) \\
\text { Uric acid }(\mathrm{mmol} / \mathrm{l})\end{array}$ & $\begin{array}{cl}2.92 & \pm 0.16 \\
0.183 & \pm 0.007 \\
14.9 & \pm 0.6 \\
2.39 & \pm 0.10\end{array}$ & $\begin{array}{l}4.59 \pm 0.41^{*} \\
0.311 \pm 0.098^{*} \\
18 \cdot 1 \pm 1.2 \\
3.73 \pm 0.23^{*}\end{array}$ & $\begin{aligned} 3.38 & \pm 0.83 \\
0.533 & \pm 0.069^{*} \\
22.4 & \pm 2.6 \\
4.59 & \pm 037^{*}\end{aligned}$ & $\begin{aligned} 1.11 & \pm 0.25^{*} \\
0.470 & \pm 0.062^{*} \\
15.9 & \pm 2 \cdot 1 \\
2.45 & \pm 0.29\end{aligned}$ \\
\hline
\end{tabular}

${ }^{*} \mathrm{P}<0.001$ compared with normal controls, using Student's $t$ test. 
Table 5 Relative supersaturation and relative probability of stone formation

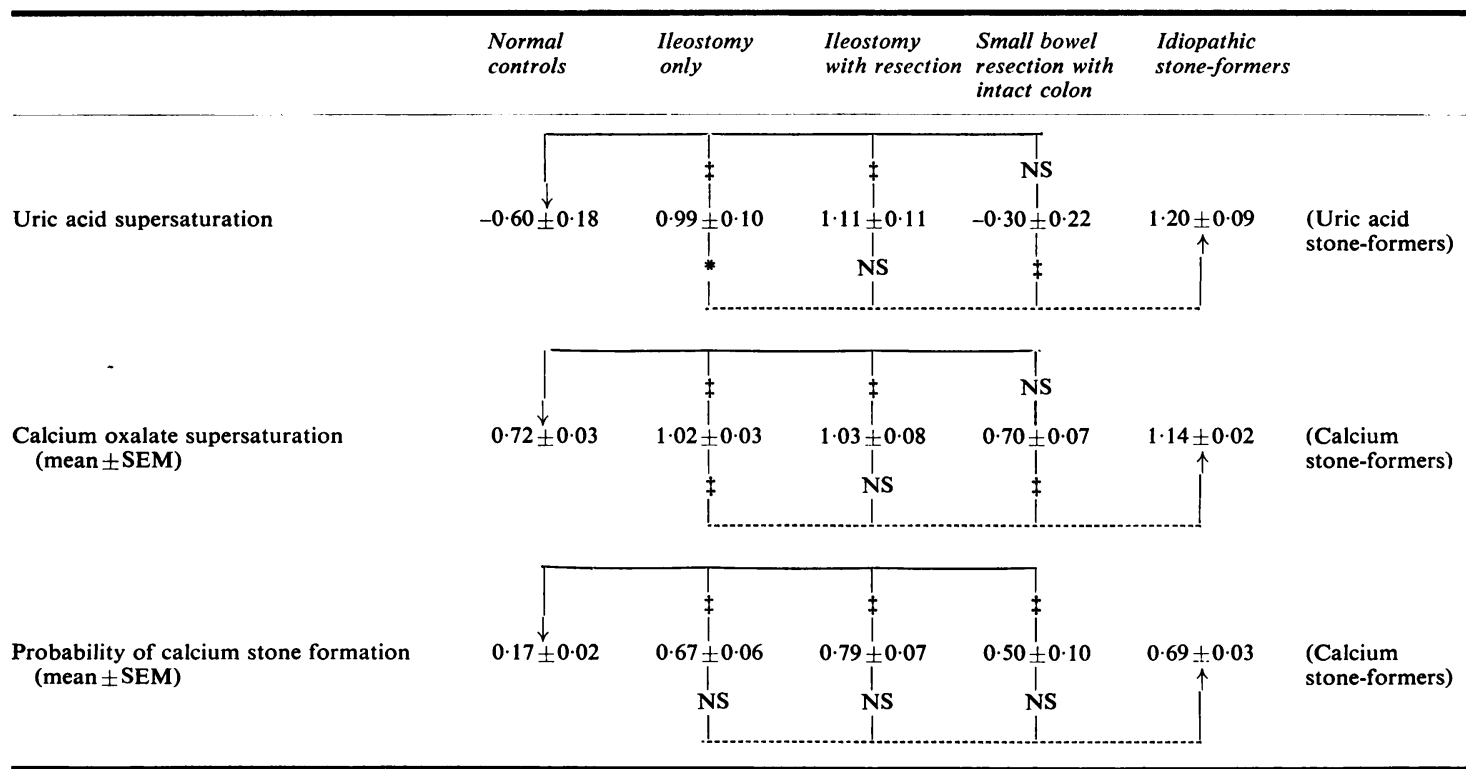

NS: not significant. $* P<0.05$. $\quad+P<0.01 . \quad \ddagger P<0.001$. Using the Wilcoxon sum of ranks test.

The continuous lines indicate the comparison of the study groups with normal controls and the broken lines indicate the comparison of the study groups with idiopathic stone formers.

calcium oxalate stone formers are shown in Table 5. There was considerable overlap between all five groups. Statistical analysis showed a significant

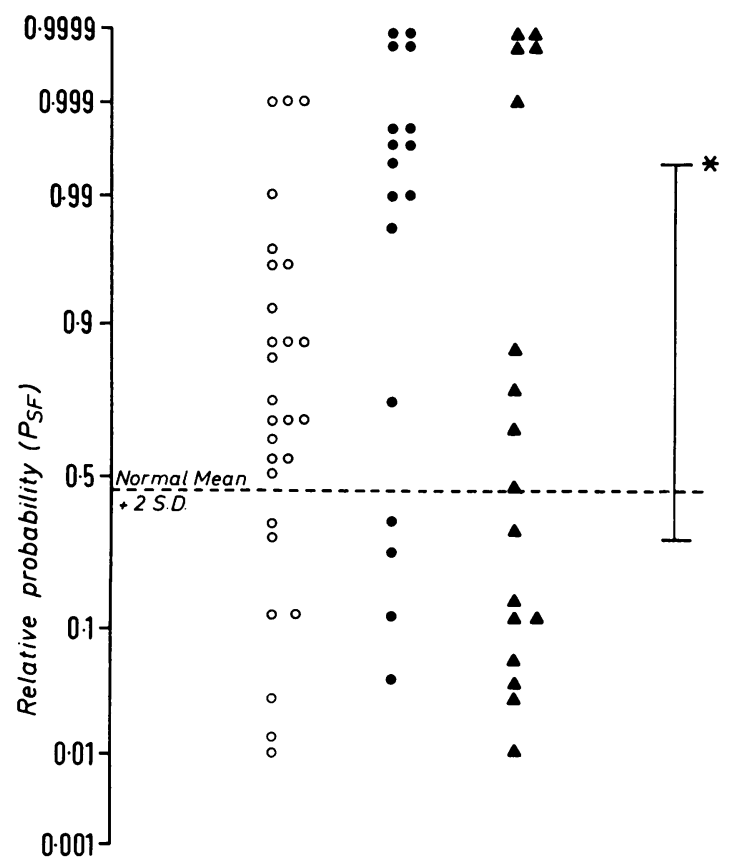

increase in calcium oxalate supersaturation in the two groups of ileostomy patients compared with the normal controls $(\mathbf{P}<0.001)$ but there was no difference between the resection with intact colon group and normal controls. There was no significant difference between the two groups of ileostomy patients. However, the ileostomy-only group had significantly lower values than the idiopathic calcium stone-formers $(P<0.001)$, whereas the ileostomy with resection group did not.

The results for PSF for the three groups of patients, the absolute range of values for the idiopathic calcium stone formers and the upper limit of the normal range are shown in the Figure. The means $( \pm$ SEM) for all groups are shown in Table 5 . The three study groups had significantly higher values than the normal controls $(\mathrm{P}<0.001$ for ileostomy patients; $\mathrm{P}<0.01$ for the group with a colon). The values for the three study groups were

Figure The overall relative probability of forming calcium stones (PSF) in ileostomy patients, with and without small bowel resection, patients with small bowel resection and an intact colon, normal controls, and idiopathic calcium stone-formers. OIleostomy only group. -Ileostomy plus small bowel resection group. $\Delta$ Small bowel resection with intact colon group. *Absolute range for idiopathic calcium stone-formers. 
similar and overlapped with those of the idiopathic calcium stone-formers but a larger percentage of patients in the study groups were within the normal range compared with the number of idiopathic calcium stone-formers within the normal range. Statistical analysis showed no significant difference between these four groups.

The weight of the 24 hour ileostomy output for the ileostomy-only group was $660 \pm 40 \mathrm{~g}$ (mean \pm SEM) which was significantly lower $(\mathrm{P}<0.001)$ than the output of $1240 \pm 112 \mathrm{~g}$ (mean \pm SEM) for the ileostomy with resection group.

Stool weights were not obtained from the resection with intact colon group; however, the mean number of stools per day was three (range one to 10).

\section{Discussion}

Our results show that the effect of an ileostomy on urinary composition is to reduce $\mathrm{pH}$ and volume. The reduced volume produces increased concentrations of calcium, oxalate, and uric acid resulting in an increased risk of forming both uric acid and calcium stones through the effect on the saturation of urine with these salts. The effect of a small bowel resection in the presence of an ileostomy is to reduce urinary volume further and to reduce urinary calcium. These changes balance out and there is no significant alteration in the uric acid and calcium oxalate relative supersaturation. Patients with small bowel resection and an intact colon maintain normal urinary volume and $\mathrm{pH}$ and have no increased risk of forming calcium oxalate stones. In the majority of patients this is due to hyperoxaluria and in others low GAG inhibitors are a factor.

The demonstration of persistently acid urine of low volume and increased uric acid concentration in this group of healthy ileostomy patients confirms the finding of Clarke and McKenzie ${ }^{10}$ that the ileostomy itself causes a persistent loss of water, sodium, and bicarbonate and produces those changes in urinary composition which favour the production of uric acid stones. The $\mathrm{pK}$ of uric acid is 5.42 and only 11 out of 44 ileostomy patients had a urinary $\mathrm{pH}$ above this value.

In the patients with small bowel resection, in spite of the higher ileostomy output, the $\mathrm{pH}$ of urine was not lowered further. An increased excretion of acid may have occurred through increased production of ammonium ions. ${ }^{10}$ Urinary volume was significantly reduced, however, producing higher concentrations of constituents and is probably the major urinary risk factor in this group accounting for the highest prevalence of stone in the three groups (Table 2). The urinary conservation of sodium was greater, producing a very low sodium excretion and reversal of the normal sodium-potassium ratio (Table 3).

Urinary $\mathrm{pH}$ and uric acid concentration determine the level of uric acid saturation and are the main factors in the formation of uric acid stones. If the supersaturation index is above a value of 1.0 , crystals will form spontaneously in the urine, between zero and 1.0 established crystals may grow and aggregate, and below zero any crystal previously formed will dissolve. ${ }^{20}$ The supersaturation indices are significantly greater than normal for both groups of ileostomy patients and approach those of idiopathic uric acid stone-formers. We would suggest that there would be a high incidence of uric acid stones if these patients were followed-up for a long period of time.

Because the colon absorbs fluid and electrolytes, patients with small bowel resection and an intact colon have lower stool volumes than ileostomy patients and remain in sodium and water balance with less dependence on renal compensatory mechanisms. ${ }^{25}{ }^{26}$ There is therefore no increase in the risk of forming uric acid stones in this group of patients, as urinary $\mathrm{pH}$ and volume are normal.

The changes in urinary composition which are most important in the formation of calcium stones are an increase in the urinary concentrations of calcium and oxalate, an increase in $\mathrm{pH},{ }^{27}$ and a decrease in concentration of the GAG inhibitors, ${ }^{28}$ the activity of which are reduced by high concentrations of uric acid. ${ }^{28}$ Because of a normal urinary volume the patients with small bowel resection and intact colon have the lowest prevalence of stones in the three groups (Table 2), although the greater the length of small bowel resected the higher the incidence of stones will be in this group.

We have shown that the excretion of calcium is normal in patients with an ileostomy with no resection of the small bowel but is significantly reduced in both groups of patients who have a small bowel resection. This reflects malabsorption of dietary calcium probably due to abnormal metabolism of bile salts and vitamin $D .^{29}$

The net effect of the changes in urinary volume and calcium excretion is to increase urinary calcium concentration in the patients with only an ileostomy, to maintain normal concentration in the patients with an ileostomy and small bowel resection, and to decrease the concentration in the patients with small bowel resection and an intact colon. However, oxalate concentration in the urine is significantly raised in all groups, because of low urine volume in the ileostomy patients and increased 24 hour excretion of oxalate in the group with an intact colon. A decrease in urinary volume and increase in urinary oxalate excretion have been shown to be the 
most critical factors in the development of calcium stones. ${ }^{21}$ Thus the net effect of these changes in urinary composition is to increase the PSF levels of calcium stone formation in all three groups.

The inverse relationship between urinary calcium and oxalate in the patients with small bowel resection supports the 'solubility' theory of enteric hyperoxaluria. ${ }^{1430}$ According to this theory oxalate is normally bound to calcium in the lumen of the small bowel through the formation of an insoluble salt, leaving only a small amount of oxalate available for absorption. In the presence of steatorrhoea calcium is bound to fatty acids leaving relatively more oxalate unbound and available for passive absorption.

The normal 24 hour excretion of oxalate in our patients with small bowel resection and an ileostomy and the increased excretion in our patients with small bowel resection but with an intact colon supports the theory that the colon is the major site for the increased absorption of oxalate after small bowel resection..$^{14} 30$

Our studies demonstrate the marked effect of intestinal resection on the composition of urine. The high levels of urinary risk factors for both uric acid and calcium stone formation found in our patients suggest that the majority of these patients have a high risk of forming a urinary stone during the remainder of their lifetime. This is supported by the $9.4 \%$ prevalence of stones in the population studied by postal questionnaire and the $9.8 \%$ prevalence of stones observed during a mean follow-up period of only seven years in the patients in whom urinary composition was studied. While a potential metabolic problem such as urinary stones cannot be considered as a major determinant of the extent of resection, nevertheless, it should be appreciated that maximal preservation of both small and large intestine reduces the risk of urinary stone formation.

After the resection, patients with an ileostomy, particularly those with small bowel resections should have regular measurements of ileostomy output and urinary volume and composition. If ileostomy losses are consistently above the normal range for body size, ${ }^{31}$ and recurrent Crohn's disease, intra-abdominal sepsis and intestinal obstruction have been excluded, loperamide and/or codeine phosphate should be prescribed to reduce ileostomy volume. In addition, all ileostomy patients should be advised to drink sufficient water to increase urinary volume without increasing ileostomy output ${ }^{32}$ and alkalinisation of the urine may be indicated in selected patients. Such treatment should not only prevent further stone formation but may also dissolve uric acid stones in situ.

Patients with small bowel resection and an intact colon should be prescribed a diet to reduce the urine oxalate. There is general agreement that the diet should be low in oxalate and fat ${ }^{16}$ and it may be that a high calcium intake will also be of value. Further stone formation can be prevented, though it will be impossible to dissolve calcium oxalate stones in situ.

We would like to thank Anne Rurtherford and Valerie Sergeant for technical assistance, David Rose for help with the collection of samples, and Professor D Johnston for his support of the study. The work was supported by a grant from Travenol Laboratories Limited and CPB is the current holder of the Royal Australasian College of Surgeons' Edward Lumley Research Fellowship.

\section{References}

${ }^{1}$ Deren JJ, Porush JG, Levitt MF, Khilnani MT. Nephrolithiasis as a complication of ulcerative colitis and regional enteritis. Ann Intern Med 1962; 56: 843-53.

${ }^{2}$ Maratka Z, Nedbal J. Urolithiasis as a complication of the surgical treatment of ulcerative colitis. Gut 1964; 5: 214-7.

${ }^{3}$ Gelzayd EA, Breuer RI, Kirsner JB. Nephrolithiasis in inflammatory bowel disease. Am J Dig Dis 1968; 13: 1027-34.

${ }^{4}$ Bennett RC, Hughes ESR. Urinary calculi and ulcerative colitis. Br Med J 1972; 2: 494-6.

${ }^{5}$ Scott R, Freeland R, Mowat W, Gardiner M, Hawthorne V, Marshall RW, Ives JGJ. The prevalence of calcified upper urinary tract stone disease in a random population-Cumbernauld health survey. $\mathrm{Br} J$ Urol 1977; 49: 589-95.

${ }^{6}$ Burkland CE, Rosenberg ML. Survey of urolithiasis in the United States. J Urol 1955; 73: 198-207.

${ }^{7}$ Melick RA, Henneman PH. Clinical and laboratory studies of 207 consecutive patients in a kidney stone clinic. N Engl J Med 1958; 259: 307-14.

${ }^{8}$ Prien EL. Crystallographic analysis of urinary calculi: a 23 year survey study. J Urol 1963; 89: 917-24.

${ }^{9}$ Bennett RC, Jepson RP. Uric acid stone formation following ileostomy. Aust NZ J Surg 1966; 36: 153-8.

${ }^{10}$ Clarke AM, McKenzie RG. Ileostomy and the risk of urinary uric acid stones. Lancet 1969; 2: 395-7.

${ }^{11}$ Admirand WH, Earnest DL, Williams HE. Hyperoxaluria and bowel disease. Trans Assoc Am Phys 1971; 84: $307-12$.

${ }^{12}$ Smith LH, Fromm H, Hofmann AF. Acquired hyperoxaluria, nephrolithiasis and intestinal disease. Description of a syndrome. $N$ Engl J Med 1972; 286: 1371-5.

${ }^{13}$ Dickstein SS, Frame B. Urinary tract calculi after intestinal shunt operations for the treatment of obesity. Surg Gynecol Obstet 1973; 136: 257-60.

${ }^{11}$ Dobbins JW, Binder HJ. Effects of bile salts and fatty acids on the colonic absorption of oxalate. Gastroenterology 1976; 70: 1096-100. 
${ }^{15}$ Ernest DL, Johnson G, Williams HE, Admirand WH. Hyperoxaluria in patients with ileal resection: an abnormality in dietary oxalate absorption. Gastroenterology 1974; 66: 1114-22.

${ }^{16}$ Andersson H, Filipsson S, Hulten L. Urinary oxalate excretion related to ileocolic surgery in patients with Crohn's disease. Scand J Gastroenterol 1978; 13: 465-9.

${ }^{17}$ Smith LH. Application of physical, chemical and metabolic factors to the management of urolithiasis. In: Fleisch H, Robertson WG, Smith, LH, Vahlensieck W, eds. Urolithiasis research. New York and London: Premium Press, 1976: 199-211.

${ }^{18}$ Coe FL. In: Nephrolithiasis. Chicago: Year Book Medical Publishers, 1978.

${ }^{19}$ Robertson WG, Peacock M, Heyburn PJ, Marshall DH, Clark PB. Risk factors in calcium stone disease of the urinary tract. Br J Urol 1978; 50: 449-54.

${ }^{20}$ Marshall RW, Robertson WG. Nomograms for the estimation of the saturation of urine with calcium oxalate, calcium phosphate, magnesium ammonium phosphate, uric acid, sodium acid urate, ammonium acid urate and cystine. Clin Chim Acta 1976; 72: 253-60.

${ }^{21}$ Robertson WG, Peacock M, Heyburn PJ, Bambach CP. Risk factors in calcium stone disease. In: Brockis JG, Finlayson B, eds. Proceedings of international urinary stone conference, Perth, 1979. In press.

${ }^{22}$ Nordin BEC, Hodgkinson A, Peacock M, Robertson WG. Urinary tract calculi. In: Hamburger J, Crosnier J, Grunfeld JP, eds. Nephrology. New York: Wiley, 1979: 1091-130.

${ }^{23}$ Robertson WG, Peacock M, Nordin BEC. Activity products in stone forming and non stone forming urine. Clin Sci 1968; 34: 579-94.

${ }^{24}$ Whiteman P. The quantitative determination of glycosaminoglycans in urine with alcian blue 8GX. Biochem $J$ 1973; 131: 351-7.

${ }^{25}$ Cummings JH, James JPT, Wiggins HS. Role of the colon in ileal resection diarrhoea. Lancet $1973 ; 1: 344-7$.

${ }^{26}$ Ladefoged K, Olgaard K. Fluid and electrolyte absorption and renin-angiotensin-aldosterone axis in patients with severe short bowel syndrome. Scand J Gastroenterol 1979; 14: 729-35.

${ }^{27}$ Robertson WG, Nordin BEC. Physiochemical factors governing stone formation. In: Williams DI, Chisholm GD, eds. Scientific foundations in urology. London: Heineman, 1976: 254-67.

${ }^{28}$ Robertson WG, Knowles CF, Peacock M. Urinary acid mucopolysaccharide inhibitors of calcium oxalate crystallisation. In: Fleisch H, Robertson WG, Smith LH, Vahlensieck W, eds. Urolithiasis research. New York: Plenum Press, 1976: 331-4.

${ }^{29}$ Compston JE, Horton LWL, Ayers AB, Tighe JR, Creamer R. Osteomalacia after small intestinal resection. Lancet 1978; 1: 9-12.

${ }^{30}$ Chadwick VS, Modha K, Dowling RH. Mechanism for hyperoxaluria in patients with ileal dysfunction. $N$ Engl J Med 1973; 289: 172-6.

${ }^{31}$ Hill GL, Millward SF, King RFGJ, Smith RC. Normal ileostomy output: close relation to body size. $\mathrm{Br}$ Med $J$ 1979; 2: 831-2.

${ }^{32} \mathrm{Hill}$ GL. Normal ileostomy physiology. In: Ileostomy, surgery, physiology and management. New York: Grune \& Stratton, 1976; 69. 